\title{
Erratum to: Effect of Equal Channel Angular Pressing on the Fracture Behavior of Commercially Pure Titanium
}

\author{
I. SABIROV, R.Z. VALIEV, I.P. SEMENOVA, and R. PIPPAN
}

DOI: $10.1007 / \mathrm{s} 11661-010-0178-6$

(C) The Minerals, Metals \& Materials Society and ASM International 2010

\section{Erratum to: METALLURGICAL AND MATERIALS \\ TRANSACTIONS A DOI 10.1007/s11661-009-0111-z}

IN the Conclusions section, first paragraph, the last sentence is corrected as follows:

The increase of deformation temperature from room temperature to $250{ }^{\circ} \mathrm{C}$ does not significantly affect the total crack growth resistance of the coarse grained $\mathrm{Ti}$, which decreases from 395 to $352 \mathrm{~kJ} / \mathrm{m}^{2}$, whereas in the UFG CP $\mathrm{Ti}$, this parameter increases from 69 to $330 \mathrm{~kJ} / \mathrm{m}^{2}$.

I. SABIROV, Researcher, is with the Instituto Madrileño de Estudios Avanzados de Materiales (IMDEA-Materiales), 28040 Madrid, Spain. Contact e-mail: ilchat.sabirov@imdea.org R.Z. VALIEV, Director, and I.P. SEMENOVA, Senior Researcher, are with the Institute of Physics of Advanced Materials, Ufa State Aviation Technical University, 450000 Ufa, Russian Federation. R. PIPPAN, Senior Researcher and Vice Director, is with the Erich Schmid Institute of Materials Science, Austrian Academy of Sciences, 8700 Leoben, Austria.

The online version of the original article can be found under doi: 10.1007/s11661-009-0111-z.

Article published online January 28, 2010 